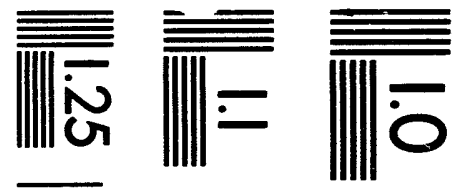

$$
\begin{aligned}
& \text { 莓|| }
\end{aligned}
$$

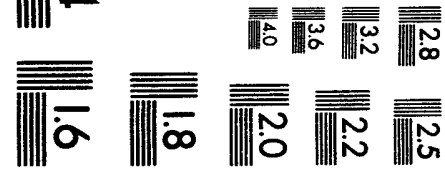



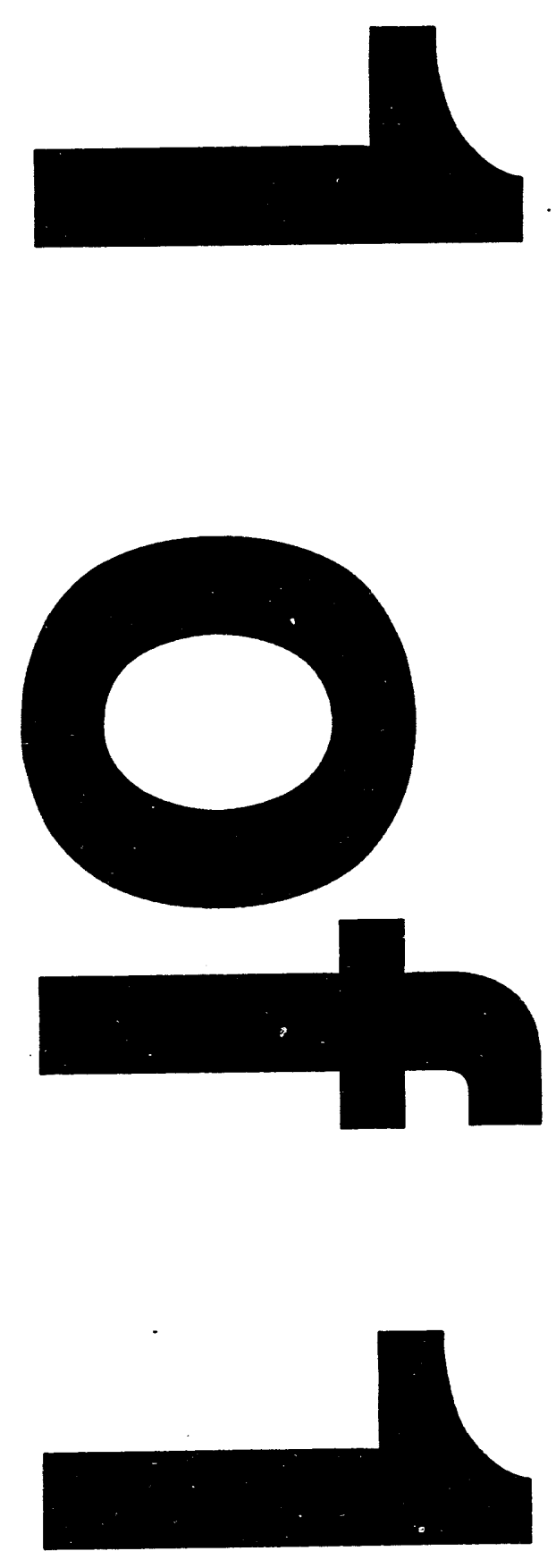


\title{
$\operatorname{Conf}-940143--2$
}

Consolidated Fuel Reprocessing Program

\section{HUMAN FACTORS IN TELEMANIPULATION: PERSPECTIVES FROM THE OAK RIDGE NATIONAL LABORATORY EXPERIENCE*}

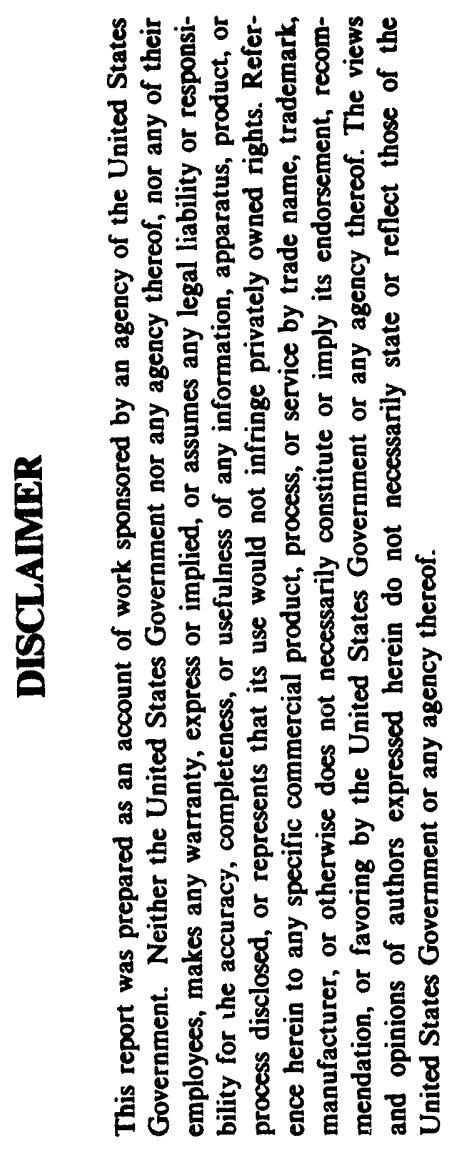

\author{
John V. Draper \\ Robotics \& Process Systems Division \\ Oak Ridge National Laboratory $†$ \\ Post Office Box 2008 \\ Oak Ridge, Tennessee 37831-6304
}

Open Literature for Proceedings at the SPIE Conference on Teleoperation and Space Telerobotics

January 1994

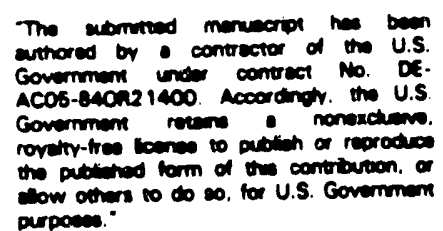

${ }^{*}$ Research sponsored by the Office of Facilities, Fuel Cycle, and Test Program, U.S. Department of Energy under contract no. DE-AC05-840R21400 with Martin Marietta Energy Systems, Inc.

†Managed by Martin Marietta Energy Systems, Inc., for the U.S. Department of Energy. 


\title{
Human factors in telemanipulation: Perspectives from the Oak Ridge National Laboratory experience
}

\author{
John V. Draper \\ Robotics \& Process Systems Division, Oak Ridge National Laboratory \\ Room 125 Building 7601 MS 6304, Oak Ridge, Tennessee 37831-2008
}

\begin{abstract}
Personnel at the Robotics and Process Systems Division (RPSD) of the Oak Ridge National Laboratory (ORNL) have extensive experience designing, building, and operating teleoperators for a variety of settings, including space, battlefields, nuclear fuel reprocessing plants, and hazardous waste retrieval. In the course of the last decade and a half, the RPSD designed, built, and operated 4 telemanipulators (M-2, ASM, LTM, CESAR arm) and operated another half dozen (M-8, Model 50, TOS SM-229, RM-10, PaR 5000, BilArm 83A). During this period, human factors professionals have been closely integrated with RPSD design teams, investigating telemanipulator feedback and feed forward, designing cockpits and control rooms, training users and designers, and helping to develop performance specifications for telemanipulators. This paper presents a brief review of this and other work, with an aim towards providing perspectives on some of the human factors aspects of telemanipulation. The first section of the paper examines user tasks during supervisory control and discusses how telemanipulator responsiveness determines the appropriate control metaphor for continuous manual control. The second section provides an ecological perspective on telemanipulator feedback and feed-forward. The third section briefly describes the RPSD control room design approach and how design projects often serve as systems integrators.
\end{abstract}

\section{CONTROLS}

Human factors is the science concerned with understanding how people relate to the machines they use, and it is the technology concerned with designing machines that best match human capabilities and limitations. Telemanipulation presents special human factors challenges because the relationship between the user and the machine is so intimate; in no other type of system does the user completely depend on displays for feedback and ask the machine to mimic his actions, rather than act on his decisions. The user must be able to work as if present in the remote area, when in fact he may be a great distance from it.

Personnel at the Robotics and Process Systems Division (RPSD) of the Oak Ridge National Laboratory (ORNL) have extensive experience designing, building, and operating teleoperators for a variety of settings, including space ${ }^{1}$, battlefields ${ }^{2}$, nuclear fuel reprocessing plants ${ }^{3}$, and hazardous waste retrieval ${ }^{4}$. In the course of the last decade and a half, the RPSD designed, built, and operated 4 telemanipulators (M-2, ASM, LTM, CESAR arm) and operated another half dozen (M-8, Model 50, TOS SM-229, RM-10, PaR 5000, BilArm 83A); and the RPSD is currently designing other telemanipulators and teleoperated vehicles. During this period, human factors professionals have been closely integrated with RPSD design teams, investigating telemanipulator feedback and feed forward, designing cockpits and control rooms, training users and designers, and helping to develop performance specifications for telemanipulators. This paper presents a brief review of this and other work, with an aim towards providing perspectives on some human factors aspects of telemanipulation.

\subsection{Telemanipulators}

According to one definition, "a teleoperator is a general-purpose, dexterous, man-machine system that augments man by projecting his manipulatory and pedipulatory capabilities across distance and through physical barriers into hostile environments." ${ }^{5}$ Master/slave telemanipulators have been defined as "general-purpose mechanical device[s] used by a human user in a normal environment to extend his hand and arm manipulative capacity into a ... remote hostile environment with the aid of direct or indirect visual observation, with movements characterized by [1] naturalness, to obviate the need for extensive training, [2] feel, to reflect the elastic characteristics of task objects and forces exerted on them, and [3] compliance, to follow task-constrained paths or orientations." 6 These definitions emphasize three aspects of teleoperators, and particularly telemanipulators, that are important in distinguishing them from other systems. First, telemanipulators are general purpose machines, capable of performing a wide array of tasks, which distinguishes them from tools like shovels, forks, or scalpels. In fact, telemanipulators can use these tools for the specific uses for which they were intended: a telemanipulator is a tool that uses tools. Second, telemanipulators are dexterous, having components that allow them to 
interact with their environment, which distir-lishes them from other remotely controlled systems like garage door openers. Third, telemanipulators are human-machine systems, combining powerful human sensory and problem-solving capabilities with the environmental hardiness or expendability of machines, a combination that distinguishes them from robots. Because telemanipulators take advantage of human intelligence, they are able to respond to the environment flexibly and develop new behaviors as required, without endangering humans by requiring their presence at hazardous sites.

\subsection{The Role of Human Factors/Ergonomics}

Telemanipulator development may take (1) the minimalist approach that only TV viewing and a joystick coupled to a modified industrial robot are necessary to perform tasks, (2) the more-is-better approach that attempts to provide a full spectrum of sensory feedback and dexterity matching the human user, or (3) a mission orientation that acknowledges design tradeoffs between capability and cost, and seeks efficient methods for doing the job. The latter approach seems most reasonable and, therefore, the challenge for human factors practitioners in telemanipulation, along with the normal human factors challenges, is to provide an evaluation of the performance benefits of adding telemanipulator capabilities. The psycho-cybernetic mode ${ }^{7,8}$ is useful when considering the human factors of telemanipulation in this context. The essence of the model is that during goal-directed actions humans respond to information present in the environment (feedback) by manipulating the environment (feed-forward). This changes the feedback and elicits another feed-forward response. Humans conduct the feed-forward with the aim of controlling the feedback: this is a continuous or continuously sampled process that persists until reaching some feedback goal. Perturbations occur when the expected relationship between feed-forward and feedback is altered. During telemanipulation this occurs in three ways: (1) temporal perturbations, in which the timing of feedback and feed-forward are different than expected; (2) spatial perturbations, in which the spatial relationships between feedback and feed-forward are different than expected, and (3) filtering, in which the amount of information in the feedback or feed-forward is in some way different than expected. An example of the latter occurs when users view a scene by television: because a television presents images as mosaics with a finite number of elements, the amount of information afforded is less than that afforded during direct viewing. In effect, the television is a low-pass filter on visual information. Training and practice may ameliorate, but cannot eliminate, the effects of perturbations. From the psycho-cybernetic model perspective, the goal of human factors in telemanipulation is to identify perturbations, quantify their effects, and analyze the trade-offs of potential alternatives. The aim of the process should be to optimize the machine for its mission by reducing perturbations as far as is economically appropriate.

\subsection{Supervisory Control}

In the future, artificial intelligence will become increasingly integrated into telemanipulators. This will lead to the development of what have been termed telerobotic systems. Telemanipulators will become capable of serving as expert assistants to the human user, completing simple tasks autonomously, or providing rudimentary reflexes. The circuinstance occurring when a computer makes decisions about system actions independently and the human user is responsible for programming has been termed supervisory control. ${ }^{9}$ This implies that the system is supervising what the person does; it also connotes circumstances in which the human communicates at a symbolic level with the machine, providing it with directions but not continuously controlling it. At a more detailed level necessary for human factors evaluations, during supervisory control of a telemanipulator a user carries out some varying mix of five tasks: (1) programming, storing a behavioral repertoire via symbols, including words; (2) teaching, storing a behavioral repertoire by stepping through examples; (3) controlling, continuous manual control; (4) commanding, control via manipulating symbols to trigger behavioral repertoires; and (5) monitoring, observing the machine carry out commands and deciding to switch to one of the other tasks as required. Currently, the primary responsibility of the human is to provide skilled motor inputs to perform tasks requiring dexterous manipulation of objects in the remote area, or controlling. In the foreseeable future, the intelligence added to telemanipulators is likely to be fairly specific and will allow the machine to make decisions under limited conditions. The purpose of this will be to assist the user in completing tasks during periods when workload is high. Autonomy may eventually expand to allow the telemanipulator to perform tasks without motor inputs from the human; the human role in such systems will be monitoring and commanding. The user may issue a fairly general command to the machine ("replace module number 10") and it will execute the command while the human monitors the progress of the task and assists the machine if necessary. However, controlling will continue to be the most important human role in telemanipulation for some time to come. 


\subsection{Control Metaphors: Arm/Hand Extension or Flying}

Metaphors help us organitie our thoughts about the world around us; they exert a powerful influence on our approach to problem solving. Therefore, it is worth considering the metaphors that may be applied to telemanipulation. When the human user is in constant manual control of a telemanipulator, one of two control metaphors may apply. The user may move the machine as if it was an extension of his arms and hands into the remote environment (in the case of exoskeletal master controllers, this is like donning a suit); or he may fly the end-effector as if it was a vehicle in 3-dimensional space. In the $\mathrm{arm} / \mathrm{hand}$ extension metaphor, the user makes the movements he might make to do the task by hand, and expects the machine to mimic his movements. In the flying metaphor, the user makes control inputs and expects the end-effector to move in the direction and at the rate he selects. The performance capabilities of the machine should determine the choice of the optimal control metaphor (arm/hand extension or flying), but a priori user preferences may also be a consideration. In either case. control of discrete joints, whether by joystick, switches, potentiometers, or other method, should be avoided because it is inefficient ${ }^{10,11,12,13}$.

Responsiveness is the ability of a manipulator to reproduce arm trajectories and impedance in time and space. Telemanipulators fall into three categories according to how well they can follow human trajectories: (1) user-paced telemanipulators are highly responsive and capable of executing any human trajectory in real time; (2) machine-paced telemanipulators are moderately responsive and are capable of executing most, but not all, trajectories in real time; and (3) non-real-time telemanipulators are not capable of keeping up with human trajectories at any pace. User-paced telemanipulators and machine-paced telemanipulators in the upper range of responsiveness for the category are more efficient when controlled using position control than when using rate control ${ }^{14.15}$, that is, the arm/hand extension metaphor is better than the flying metaphor. However, the work envelope for a position controller must be adequately large to span the task area. If the user frequently meets a work envelope barrier and must index the master and slave (indexing ratchets the slave position relative to the mastar controller) performance is no better than with a rate controller. In one experiment ${ }^{16}$, there were no performance differences between position controllers and rate controllers for the same slave arm and subjects complained of the constant indexing necessary to complete the task with the small-volume master controller used. Nearly all master controller operations take place within a volume resting on the user's lap and approximately $3 / 4$ meter wide, $3 / 4$ meter high, and 1 meter deep ${ }^{17}$; the work envelope should probably never be smaller than this. Rate control (the flying metaphor) is best for machine-paced telemanipulators that are in the lower range of responsiveness for the category and non-real-time telemanipulators, because rate control encourages slow, careful movements, and because unresponsive systems may develop dangerous lags between master and slave, which are easier to deal with using rate control than position control.

\subsection{Feedback Metaphors: Cybernetic or Experiential Telepresence}

Feedback metaphors seem to depend on the interpretation of the term telepresence. In the simple definition, telepresence means "present at a distant site" and refers to teleoperation generally. A cybernetic definition speaks of telepresence as an index of the quality of the human-machine interface: telepresence occurs when "the operational characteristics of the human-computer/human-telerobot interface [are] compatible with the behavioral-physiological performance capabilities and limitations of the human user." 8 High fidelity telepresence occurs in the absence of spatial and temporal perturbations in feedback and feed forward and (presumably) telepresence fidelity is degraded as perturbations are introduced. An experiential definition speaks of telepresence as a mental state entered when telemanipulator dexterity is equivalent to human dexterity and sensory feedback has sufficient scope and fidelity to convince a user that he is physically present at the remote site ${ }^{18}$. This has also been described as a "sense of being physically present with virtual objects at the remote teleoperator site," 19 as an "illusion" occurring when the user "feels physically present at the remote site, 20 and as the "real-time sensation of remote presence." 21 The distinguishing characteristic of experiential telepresence is the mental state involving the suspension of the user's awareness of the remoteness of the remote site.

Cybernetic telepresence fits in well with a mission-oriented approach to telemanipulation, because it considers available feedback and feed forward to make performance predictions. Experiential telepresence is less useful, for four reasons. First, experiential telepresence seems indistinguishable from the experience called "flow," in which a person becomes so engrossed in his activities that he loses self-awareness ${ }^{22,23,24}$. Flow experiences may occur while working with any system, including teleoperators that are not very dexterous and that do not provide very good sensory feedback. They can even occur in situations where humans are not actively involved in the scenes they witness: the best examples of this are 
watching a motion picture or "by clever storytelling." 25 It may be that the likelihood of encountering a flow experience during telemanipulation increases with feedback fidelity and dexterity but other factors, perhaps including the importance of the task, the suggestibility of the user, or even the time of day may also affect the likelihood of experiencing flow. However. there is no evidence that experiential telepresence is a special state different from that achievable in more mundane circumstances or that users benefit from the experience. Second, any performance benefits attributable to experiential telepresence would be more directly attributable to feedback fidelity and dexterity without invoking an intermediary mental state. Third, even assuming that experiential telepresence is unique and beneficial, using it as a design ideal is akin to expecting that every airplane should be an F-15 or every automobile a Ferrari Testarossa: this approach neglects the technological and economic realities by emphasizing an a priori design goal not related to the mission of the telemanipulator. Designing for experiential telepresence places too much emphasis on the telemanipulator and is "too narrow to deal with the capabilities and specification of ... teleoperation." ${ }^{26}$ To continue the analogy, in some cases a Piper Cub or a pickup truck is the optimal design solution: an F-15 would not make a good air ambulance and a Ferrari would not be effective hauling cattle. Furthermore, it is difficult to reconcile experiential telepresence with telerobotics and supervisory control; it is hard to imagine how a user will feel truly present and active in the remote area when watching the machine perform tasks robotically. Fourth and finally, experiential telepresence may be counterproductive: for example, in a supervisory control system a certain detachment may be required to keep the user from becoming so immersed in controlling that he resists returning to monitoring. Full presentation of remote events may also be stressful and make performance poorer ${ }^{27}$. Because experiential telepresence is redundant, encourages reference to indirectly causal relationships, and encourages a sub-optimal design strategy, it has little utility.

\section{FEEDBACK AND FEED-FORWARD}

\subsection{The Contingency Web}

A telemanipulator, its human crew, the tasks it is designed to perform, and the environments occupied by the crew and by the task form a very complex system. The task is embedded in the remote environment, the telemanipulator is embedded in the task, and the user is embedded in the telemanipulator and the local environment. There exists a complex web of contingencies connecting the parts of the system and determining how each component and sub-system performs. Neither the major components (i.e. crew, telemanipulator, task, remote environment, local environment) nor the sub-systems comprising these components may change without sending ripples through the entire system. For example, the difference in control metaphors has an impact on where televisison cameras should be placed and on what they should look at; for the arm/hand extension metaphor, cameras should provide views similar to the normal human view of the hands. Cameras should be place near the shoulders of the slave arms. For the flying metaphor, it is more appropriate to have a camera attached to the end-effector, in a position similar to that of an aircraft cockpit. The contingency web connects telemanipulator responsiveness to the control metaphor to camera placement, etc. This is an ecological perspective that contends that there is no single "best way" to provide feedback or feed forward during telemanipulation; rather, the sub-systems must be matched to provide the most efficient and economical system for completing the intended mission of the telemanipulator.

\subsection{Feedback}

Nowhere is need for an ecological perspective more apparent than study of feedback provided to telemanipulator crews. Discussion of telemanipulator feedback will concentrate on two critical areas: vision systems and force feedback. Remote viewing is essential for telemanipulation and force feedback, though not required for good telemanipulation, is helpful in many applications. Audition may also be a useful channel but the information afforded by sound is limited and often easily provided by visual displays. For example, one may be able to tell roughly how hard a motor is working by its sound but a tachometer is more efficient.

Vision Systems, Mono-image television (MTV) is sufficient for telemanipulation but it provides users with one view of remote areas to both eyes, while normal human vision includes two slightly different views because of the separation between the eyes. This difference in images is important because it produces a cue to distances called retinal disparity. Some researchers suggest stereoscopic television (STV) as a desirable alternative to MTV because it displays two different views of the remote area, one to each eye, and therefore prnvides retinal disparity cues (and convergence cues as well). The geometric principles involved in presenting an accurate ste sscopic representation of space and the distortions produced by failing to 
properly control viewing system geometry are well known $\mathrm{n}^{28.29}$; however, the methods used by the human visual system to prioritize and integrate the available cues in a televised scene are not as well understood. Although retinal disparity is not available with MTV, other sources of depth information are. Therefore, it is not correct to associate depth perception solely with STV, because depth perception is possible with MTV using cues like perspective, interposition, shadows, and object size. The richness of all the cues available in a scene, not just the binocular ones, determines the accuracy of distance estimates and the subjective experience of depth. As has been said, "It is obvious that in a full-cue viewing situation, where there is a rich and redundant set of cues indicating object distances and identities, it would be possible to take away several redundant cues without taking away depth perception." 30 There is also evidence that monocular depth cues are more powerful than binocular depth cues under some circumstances, specifically when judging distances between objects on a single plane, and as powerful as binocular cues under most circumstances ${ }^{31}$. Furthermore, there is evidence that increasing viewing system resolution is at least as important as providing stereoscopic images for remote handling tasks and visual inspections ${ }^{32}$. Unfortunately, the impact of resolution has not been as thoroughly studied as the impact of stereoscopic images, perhaps because increasing resolution requires a more extensive modification of existing televisions.

The debate on the utility of stereoscopic television for telemanipulation has two fundamental positions. One position is that stereoscopic television affords users more information about the remote area and, therefore, must allow improved telemanipulator performance. From this position, experiments that have failed to demonstrate the STV advantage have lacked power or used poorly designed viewing equipment. The second position is that STV affords users more data about the remote area, and if these data are unavailable through mono-image television or more efficiently converted to meaningful information in the presence of STV, there will be an STV performance advantage. To date, a critical experiment comparing these two positions has not been performed, and in fact it is difficult to imagine data that could refute the first position. (A third position holds that STV has a negative impact on telemanipulation because it induces faticue and eyestrain, but this may be discounted as a response to sub-optimal STV design. Systems with low data rates that cause visible flicker, large inter-camera distances, poor image registration, heavy head gear, etc. can induce fatigue or eyestrain. This is an important point to remember, but it should not be construed as an indictment of STV itself.)

Certain hypotheses concerning the impact of STV on telemanipulator performance may be derived from examining the literature. First, the viewing conditions in the remote area have an impact: users seem to perform better with STV than with MTV if the task area is obscured ${ }^{33}$. However, under these conditions the important impact of STV may be to improve visibility rather than depth perception per se because of the positive impact of binocular concordance ${ }^{34}$. Second, environment and task characteristics have an impact: predictable, structured tasks and environmer is seem to afford enough information to make STV redundant, but unstructured or dynamic environments do not $34,35,36$. Third, user characteristics have an impact, because performance seems relatively unaffected by the presence of STV after practice ${ }^{31}$, perhaps because users become better at seeking out mono-image cues. Fourth, characteristics of the controlled system may have an impact: less responsive manipulators require more precise positioning, because users are not able to recover as quickly from perceptual errors. Finally, users are active information seeker ${ }^{37}$ embedded in a multi-sensory system: they may attempt to compensate for the loss of stereoscopic information by manipulating the remote environment to test and modify their world model. When the telemanipulator is responsive enough to allow this, binocular vision may not confer strong performance advantages ${ }^{38}$. To summarize, the performance advantage for STV may be inversely related to image clarity, task complexity, user skill or experience, and manipulator dexterity. However, some of these factors are not well quantified, the precise nature of the relationship between them and performance is not clear, and the interactions among these factors are unknown. The definition of performance is also important: STV may not improve task completion time, but it may make movements more accurate and hence safer.

The placement of television cameras in the remote site can also be a difficult problem. Sometimes, viewing systems have the lowest priority in design of a remote maintenance system, and as a consequence camera placement is on a spaceavailable basis. This can lead to cameras with lines of sight that are easily occluded by the manipulator or different than normal lines of sight from eyes to hands. This can have a negative effect on performance ${ }^{7}$, but only outside a fairly wide range (lines of sight within 60 degrees of the saggital plane, horizontally, and vertically from the horizon to 60 degrees above the horizon seem to have little effect on performance with telemanipulators $)^{39}$.

Force Feedback, Force feedback may be in the form of proportional force feedback or in the form of forcedistribution feedback ${ }^{40}$. Proportional force feedback presents the user with a display of force that is proportional to forces on 
the telemanipulator slave arm. Force reflection is a type of proportional force feedback in which forces applied by the slave (remote) portion of a master/slave telemanipulator are displayed to the user through back-driving the master controller. Proportional force feedback gives users a sense that is not directly analogous to any single human sense, but combines elements of tactition and kinesthesia. Force-distribution feedback provides a display of forces that matches the distribution of forces on the manipulator (usually the manipulator end-effector); it gives users a sense of touch. Some human factors principles of dynamic tactile displays for providing force-distribution feedback have been described ${ }^{41}$, but these devices have not been widely integrated into telemanipulators.

One experiment found some evidence for a beneficial effect of force reflection on telemanipulator performance (defined as task time and collisions with equipment in the ramote area) for simple tasks with a fairly large-scale manipulator but "Not enough data [were] taken to show conclusively that the lack of force feedback was detrimental." 42 However, the removal of force reflection following repeated task completion led to a change in style: without force reflection, users seemed to execute trajectories step-wise, making a movement and then checking manipulator position before making another input, in contrast to continuous motions observed with force reflection. Another study reported data that seemed to favor force reflection but force reflection effects were confounded with differences between the manipulators used in the force reflecting and non-force reflecting conditions ${ }^{43}$, and a third experiment that compared a single manipulator system with and without force reflection also found average differences that favored force reflection in the time required to complete tasks $\mathbf{4 4}^{4}$. A fourth experiment found that force reflection can be beneficial for users when forces in the remote area must be controlled ${ }^{45}$, but reduces task completion time only if it doesn't reduce responsiveness. In the experiment, the time required to complete tasks was not significantly shorter with force reflection but it produced significantly lower error rates and forces applied to task components. A fifth experiment found completion time differences among force reflection conditions early in an experiment that disappeared with practice ${ }^{46}$, and a more recent experiment reported similar average differences between force reflection and non-force reflection modes, but subject performance was highly variable ${ }^{47}$.

Visual displays for proportional force feedback have been demonstrated and this work has been reviewed elsewhere ${ }^{48}$. While visual displays are an inexpensive alternative, it seems that they place an additional burden on users' visual channel, which is already heavily loaded during telemanipulation. Visual presentations of force information may also be more difficult to interpret than tactile presentations. Directional auditory displays have also been investigated ${ }^{49}$.

With force-distribution feedback, there may not be an advantage in the rate of task performance, but the quality of performance (the number of errors and failed attempts at the task and the strategy used by users) may be better ${ }^{41.50}$. Without force feedback, users make frequent imprecise attempts to grasp and operate task components but users with force feedback make fewer attempts that were more precise and longer in duration.

Certain hypotheses may be stated based on observations from this literature and on the characteristics of humans as processors of information. First, information provided by force feedback can be unique or it can complement information available through other sensory channels. For example, a user attempting to tighten a bolt to a criterion torque may be able to judge when the bolt reaches this torque by feeling the reflection of resistance to turning or by viewing the dial of a torque wrench. When force feedback provides information that complements users' television views of the remote area, users are not as likely to attend to force feedback since humans tend to favor vision over the other senses. Force feedback is most helpful when it displays information that other senses (particularly vision) are unable to provide or when other displays are difficult to interpret. The greatest advantage for force feedback should occur when forces applied to the remote area are important, when task components require guidance or assembly in areas difficult to see with television cameras, and when viewing is degraded by dust, gases, lens browning, or other obscuration. Second, there appear to be fundamental differences in the strategies employed by users with and without force feedback, including step-wise trajectory inputs without force feedback and different approaches to grasping task components. It seems that users without force feedback perform tasks more tentatively than they do with force feedback. The ability to detect contact through force feedback may give the users a greater feeling of safety during operations. Unfortunately, there is also a disadvantage to force feedback: it can add to the friction and inertia of the system and thereby reduces responsiveness, or further load users' visual channels. 


\subsection{Feed-forward}

Human factors work in telemanipulation has concentrated on feedback, but the most important challenge for telemanipulator designers now may be to develop adequately responsive manipulators. In an experiment that had subjects perform a task (1) by hand with direct viewing, (2) by hand with television viewing, and (3) using a servomanipulator with television viewing, the impact of the servomanipulator by far outweighed the impact of television ${ }^{36}$. From the perspective of applying human performance data to the problem of specifying telemanipulator performance, few systematic studies have been conducted. It has been hypothesized that limitations in users' ability to develop internal representations of remote space limits telemanipulator performance ${ }^{51}$, but this seems unlikely given human ability to operate in 3-dimensional space. Feedback mechanisms are now fairly well understood: to move forward, telemanipulator researchers must concentrate on optimizing the performance of remote equipment. Human factors researchers can help by defining human performance capabilities.

During teleoperation, user inputs arise from changes in hand acceleration during execution of goal-directed trajectories. Any hand acceleration-deceleration impulse may be modeled as the summation of a set of arm link accelerations and decelerations, which are caused by muscle contractions and vary in amplitude and frequency. Bandwidth in this context is the range of frequencies that contribute significantly to the total acceleration-deceleration impulse, where significance is based on amplitude. Teleoperator responsiveness is to a large extent determined by the range of acceleration-deceleration impulse frequencies that a system can track, that is, by bandwidth. Therefore, a fundamental human factors question for servomanipulator designers is: what is the bandwidth of human acceleration impulses applied to the master controller during the cognitive and motor process that includes detection of positioning errors, selection of response strategies, and execution of these strategies? Prior research about human bandwidth during manual tracking provides information about the rate of decision-making and response execution ${ }^{52,53,54}$, and this information is important for telemanipulators operated using the flying metaphor. However, it is not directly applicable here to high-performance telemanipulators operated using the $\mathrm{arm} / \mathrm{hand}$ extension metaphor: the level of reduction is inappropriate because tracking data refer to the closed-loop bandwidth of the entire human-machine system and not the open-loop, feed-forward bandwidth of an effector system. Research about manual target acquisition tasks is more germane: teleoperator tasks may be considered as a series of target acquisitions, each requiring planning and executing a three-dimensional trajectory to move the end-effector from a starting point to a target in the remote area. Placing the socket of a wrench on a bolt is a good example. Removing a flange fastened by several bolts requires an inter-related set of these target acquisitions. Target acquisition research has demonstrated some of the invariant properties of hand trajectories $55,56,57,58$, but unfortunately this knowledge is difficult to translate into the parameters teleoperator designers need, although a survey of important parameters is available 59 . However, this line of inquiry provides a foundation for further teleoperator-related experimentation: target acquisition is a series of submovements, each comprising an evaluation of the distance to be crossed and the accuracy required, development of a motor program to execute the movement, and execution of the movement ${ }^{60}$.

The maximally responsive machine accepts forces and converts them to acceleration without modifying or constraining the input. The average acceleration-deceleration impulse bandwidth for human hand movements is $5.63 \mathrm{~Hz}$ for the first impulse and $9.20 \mathrm{~Hz}$ for subsequent impulses, and the average period is $265 \mathrm{~ms}(3.77 \mathrm{~Hz})$ for the first impulse and $218 \mathrm{~ms}(4.59 \mathrm{~Hz})$ for succeeding ones ${ }^{61}$. However, acceleration bandwidth during secondary sub-movements with a state-ofthe-art telemanipulator average only $3 \mathrm{~Hz}^{62,63}$. The most important causes of this low responsiveness were probably master controller friction and inertia imposed on the user's hand, which made movement more difficult than normal. It may also be that observing movements by television reduced the user's ability to judge distances and detect edges in the task, producing uncertainty that may have led to a reduction in the rate of acceleration impulse production to allow for closer visual monitoring of the movement. The best solution to this problem is to develop lighter master controllers or to sense hand position via sensors not mounted on the arm. However, this makes it difficult to provide force reflection, although the sacrifice may be worth the reward.

End-effector velocity is another important parameter. Users had trouble operating an early servomanipulator with a maximum velocity of $0.61 \mathrm{~m} / \mathrm{s}^{64}$ but their difficulties disappeared when gear reductions were changed to allow velocities up to $0.91 \mathrm{~m} / \mathrm{s}$. During the terminal phase (57\% of the time) of a task performed using a state-of-the-art telemanipulator users moved the master controller at much lower velocities, but during the ballistic phase (43\% of the time) $17 \%$ of the velocity observations were at or above $0.76 \mathrm{~m} / \mathrm{s}^{65,66}$. This means that a machine with a velocity limit below $0.76 \mathrm{~m} / \mathrm{s}$ will pace the 
task $17 \%$ of the time during ballistic movements. However, these data were generated using a somewhat cumbersome master controller, and velocity might be higher for a more responsive telemanipulator.

Machine performance parameters may vary within a single machine, because users move a telemanipulator using two joint clusters corresponding to a slewing cluster involving joints that moved long (arm) links and a fine-adjusting cluster involving short (wrist) links ${ }^{67}$. These clusters help explain the relative robustness of telemanipulators when examining the impact of failures on telemanipulators ${ }^{68}$. These results along with the joint velocity observations mentioned above imply that arm joints may be relatively low frequency joints with high velocity limits and wrist joints may be high frequency joints with low velocity limits.

\subsection{Other Controls}

Telemanipulator cockpits require more controls than just those for the manipulator. Transporters, tools, and television cameras, to name a few, all require controls that must be integrated into a telemanipulator cockpit. Because telemanipulation is a high-workload activity and aiming television cameras is an important secondary task that interferes with manipulator control, research on alternatives to manual control of television cameras has been conducted at several facilities. Voice control and automated end-effector tracking (cameras that automatically follow the manipulators) have been demonstrated ${ }^{69,70,71}$ for controlling telemanipulator cameras, and controlled experiments verified that these alternatives can improve task performance and reduce user workload ${ }^{72.73}$. One interesting aspect of automated tracking is that if it is continuous the user may lose any sense of slave arm movement ${ }^{74}$. This is easily resolved, however, by using a deadband area around the camera aiming angle. High telemanipulator workload has also been addressed by designing telemanipulator control rooms to include multi-operator teams ${ }^{75,76,77.78}$, and at least one short study has evaluated the nature of interactions among the crew in such a control room ${ }^{79}$.

\section{CONTROL ROOM DESIGN}

Human factors specialists at the RPSD have designed several control rooms for telemanipulators (and other systems). The RPSD approach to control room design is systematic and methodical, and it includes three distinct stages. In the first, a detailed analysis of the information and control requirements of the system is completed; in the second, an analysis of tasks to be completed by the users is made, using methods developed for nuclear power plant control rooms ${ }^{80}$ to develop an electronic task analysis database (task network simulations may also be constructed to support this); and in the third, the information generated in the first two phase is integrated, and used to support the design of the control room concept. The design phase includes development of concepts for (1) control panels, (2) rvorkstations which integrate one or more control panels, and (3) a room layout which optimizes coordination and cooperation among crew members.

Some common-sense aspects of telemanipulator control rooms have evolved over the course of our experience. First, the crew should not be unnecessarily encumbered; they should be free to move around the control room as they desire. The crew is equally embedded in the telemanipulator and the environment of the control room, and they need to be free to act within either one. Second, telemanipulation is strenuous; the system can be more efficient (i.e., provide more hours of availability) if the crew includes at least two qualified persons, who can provide an operator and a relief. In large-scale maintenance campaigns ${ }^{81}$, it has been possible for one person to operate the system continuously for 4 hours, but it is better to restrict a single user to 2 hours of operation. Third, good task visibility is sometimes difficult to achieve during remote viewing. It is not always possible to get a good view of a work site, and users may use several partial, or partially useful, views of the task. This means that it is a good idea to have more than one television monitor, so that switching can be simply attentional, without requiring a control input. Fourth, an uncluttered motion range is important for master/slave telemanipulators, both for the safety of the user and control room equipment, and for the efficient completion of tasks.

An interesting aspect of control room designing is the systems integration function often performed, at a conceptual level, during this process. Designers working on telemanipulators often seem to be compartmentalized, by sub-system if not by engineering discipline. This is more often the case when design teams are drawn from several organizations than when one group is responsible for the entire system, but there is nearly always some degree of parochialism inherent in the design process. At some point, all the sub-systems must be integrated in a fashion that lets the human user manage them as mission resources; the control room concept design process is often the catalyst for this. In a way, this is appropriate: ultimately, it is 
the human crew that is responsible for the success of a telemanipulator mission, and control over every sub-system must be effectively placed in their hands. After all, it is the human users who have the mission; the purpose of the machinery is to help them complete it.

\section{CONCLUSIONS}

Human factors usually has an impact on how the human-Inachine interface structures the user's task and on the design of the human-machine interface itself. In telemanipulation human factors can be an even more critical technology because the design of the controlled system should make use of human performance data. This makes no sense in the design of, for example, an advanced tactical aircraft because (1) there is no analogous human performance (how fast people can fly without machines), (2) powerful natural preconceptions do not mask the mental models users develop (for example, expectations about how arms behave, reinforced daily), and (3) the actions of most systems respond to the user's inputs but do not mimic the users' inputs (as is the case with highest-performance telemanipulators). As has been said 82 , "In teleoperation, the [human-machine] interaction ...is more than merely an exchange of information .. energetic interactions are at least as important."

The design of human-machine interfaces for telemanipulators is a demanding task because of the requirement for realtime reproduction of hand and arm movements but at the same time designers have considerable latitude to modify the task. In telemanipulation, television, computers, and communication links couple the user to the world in which the servomanipulator performs. The computers allow designers to modify inputs and displays many ways: for example, animations may be overlaid on television pictures to show parts of the environment obscured from the view of the television camera. It is also possible to change the scale of the work: a user could repair a heart valve, replace piping in a process plant, or capture a satellite from the same control station and within the same work envelope, if the master controllers can communicate effectively with slave arms of appropriate size for the real-world tasks ${ }^{83,84}$.

Telemanipulators are symbiotic human-robot systems that combine the capabilities of humans and robots; the ultimate justification for deploying them is economic. Economic justifications for telemanipulators include (1) liability, (2) efficiency, and (3) effectiveness. Liability is important where risks to worker health attend human access to work places and the employment of telemanipulators reduces or eliminates exposure. Efficiency must consider the costs of the maintenance approach and the difference in availability associated with competing alternatives; for human access, analysis of efficiency must not ignore the potential costs of special procedures necessary for introducing humans into the workplace (life support, medical care, travel to and from the site, etc.). Effectiveness is important because there are some tasks that people cannot do and some tasks that telemanipulators cannot do. Telemanipulators will be most successful when tasks are accompanied by hazards in the environment, require dexterity, and there is unpredictability that renders robots helpless.

Thirty years ago it was observed that the allocation of functions between humans and machines hinges on the underlying principle that "[people] are flexible but cannot be depended upon to perform in a consistent manner whereas machines can be depended upon to perform consistently but they have no flexibility whatsoever." 85 Furthermore, while allocation of functions depends upon the ability to compare human and machine performance, the two are in fact not comparable but rather complementary. The three decades of development in robotics and artificial intelligence have not altered this important point. The complementary abilities of robots, human workers, and teleoperators should all be considered when designing methods for completing missions requiring telemanipulators.

\section{ACKNOWLEDGMENTS}

This work was performed at the Oak Ridge National Laboratory, which is managed by Martin Marietta Energy Systems, Inc. for the U.S. Department of Energy under contract DE-AC05-84OR21400. The opinions expressed are those of the author, and not necessarily those of the Oak Ridge National Laboratory, Martin Marietta Energy Systems, Inc., or the U.S. Department of Energy. 


\section{REFERENCES}

1. J. N. Herndon, S. M. Babcock, P. L. Butler, and A. J. Meintel. "Telerobotic manipulator developments for ground-based space research," in Proceedings of the International Topical Meeting on Remote Systems and Robotics in Hostile Environments, Chapter 3-1, March, 1989.

2. K. U. Vandergriff and J. H. Hannah, "Technology for the future battlefield." Oak Ridge National Laboratory Review, 25(1), 1992, pp. 10-17.

3. D. P. Kuban, M. W. Noakes, and E. C. Bradley, "The Advanced Servomanipulator system: Development status and preliminary test results," Proceedings of the International Topical Meeting on Remote Systems and Robotics in Hostile Environments, pp. 638-644, March, 1987.

4. B. L. Burks, B. S. Richardson, G. A. Armstrong, W. R. Hamel, J. F. Jansen, S. M. Killough, D. H. Thompson, and M. S. Emery, "A demonstration of remote survey and characterization of a buried waste site using the SRIP testbed," in Robotics and Remote Systems: Proceedings of the Fourth ANS Topical Meeting on Robotics and Remote Systems, by M. Jamshidi and P. J. Eicker (eds.), (Sandia National Laboratory, Albuquerque. NM), 1991, pp. 179-185.

5. W. R. Corliss and E. G. Johnsen, Teleoperator Controls: An AEC-NASA Technology Survey (NASA SP-5070), (NASA Office of Technology Utilization, Washington, DC), 1968.

6. D. G. Jelatis, "Characteristics and evaluation of master-slave manipulators," in Performance Evaluation of Programmable Robots and Manipulators (NBS Special Publication 459), by T. B. Sheridan (ed.), ('ational Bureau of Standards, Washington, DC), 1975, pp 141-146.

7. T. J. Smith and K. U. Smith, "Feedback-control mechanisms of human behavior," in Handbook of Human Factors, by G. Salvendy (ed.), (Wiley, New York), pp. 251-293, 1987.

8. T. J. Smith and K. U. Smith, "The human factors of workstation telepresence," in Third Annual Workshop on Space Operations Automation and Robotics (SOAR '89) (NASA Conference Publication 3059), by S. Griffin (ed.), (National Aeronautics and Space Administration, Johnson Space Flight Center, Houston, TX), 1989, pp 235-250.

9. T. B. Sheridan and W. L. Verplank, Human and Computer Control of Undersea Teleoperators (Technical Report for the Office of Naval Research), (Massachussetts Institute of Technology, Cambridge, MA), 1978.

10. R. Goertz, Philosophy and Development of Manipulators. (Argonne National Laboratory, Argonne, IL), 1951.

11. P. L. Marjon, "Ground support equipment human factors studies," in Proceedings of the Human Factors of Remote Handling in Advanced Systems Symposium (ASD Technical Report 61-430), (Behavioral Sciences Laboratory, Aerospace Medical Laboratory, Aeronautical Systems Division, Air Force Systems Command, U.S. Air Force, Wright-Patterson AFB, OH), pp. 21 -30, 1961.

12. T. B. Malone, "Man-machine interface for controllers and end effectors," in Remotely Manned Systems: Exploration and Operation in Space, by E. Heer (ed.), (California Institute of Technology, Pasadena, CA), pp. 319-326, 1972.

13. J. V. Draper, S. Handel, E. Sundstrom, J. N. Herndon Y. Fujita, and M. Maeda, Final Report: Manipulator Comparative Testing Program (publication ORNLTM-10109), Oak Ridge, TN: Oak Ridge National Laboratory, 1987.

14. J. M. O'Hara, "Telerobotic control of a dexterous manipulator using master and six-DOF hand controllers for space assembly and servicing tasks," in Proceedings of the Human Factors Society 31st Annual Meeting (The Human Factors Society, Santa Monica, CA), pp. 791-795, 1987.

15. H. Das, H. Zak, W. S. Kim, A. K. Bejczy, and P. S. Schenker, "Operator performance with alternative manual control modes in teleoperation," Presence: Teleoperators and Virtual Environments, 1 (2), 201-218, 1992.

16. M. A. Stuart, J. M. Bierschwale, and A. J. Legendre, Space Station Hand Controller Commonality Test Report Section 2: Remote Operator Interaction Laboratory (JSC-32125), (National Aeronautics and Space Administration Lyndon B. Johnson Space Center. Houston, TX), 1991

17. R. S. Stoughton, Kinematics and Duty Cycles of the SM-229 Force-Reflecting Servomanipulator (ORNLTM-9655), (Oak Ridge National Laboratory, Oak Ridge, TN), 1986.

18. D. L. Akin, M. L.Minsky, E. D. Thiel, and C. R. Kurtzman, Space applications of automation, robotics., and machine intelligence systems (ARAMIS), Phase II, Vol. 3: Executive Summary (National Aeronautics and Space Administration, NASA Marshall Space Flight Center, Huntsville, Alabama), 1983.

19. T. B. Sheridan, "Musings on telepresence and virtual presence," Presence: Teleoperators and Virtual Environments, 1 (1), 1992,120 126.

20. T. B. Sheridan, Telerobotics, Automation, and Human Supervisory Control, (The MIT Press, Cambridge, MA), 1992 , p. 6.

21. S. Tachi, K. Tanie, K. Komoriya, and M. Kaneko, "Tele-existence (I): Design and evaluation of a visual display with sensation of presence," in Theory and Practice of Robots and Manipulators, Proceedings of the RoManSy '84: The Fifth CISM-IFToMM Symposium, by A. Morecki, G. Bianchi., and K. Kedzior (eds.), (The MIT Press, Cambridge, MA), 1985, pp. 245-254.

22. G. Privette, "Peak experience, peak performance, and flow: A comparative analysis of positive human experiences," Journal of Personality and Social Psychology, 45 (6), 1983, pp. 1361-1368.

23. M. Csikszentmihalyi, Beyond Boredom and Anxiety, (Jossey-Bass Publishers, San Francisco, CA), 1975.

24. M. Csikszentmihalyi, "Play and intrinsic rewards," Journal of Humanistic Psychology, 15 (3), 41-63, 1975. 
25. T. B. Sheridan. "Defining our terms," Presence: Teleoperators and Virtual Environments, I (2), 1992, pp. $272-274$.

26. P. Fischer, R. Daniel, and K. V. Siva. "Specification and design of input devices for teleoperation," in Proceedings of the 1990 IEEE International Conference on Robotics and Automation, (IEEE Computer Society Press, Los Alamitos, CA), 1990, pp. 540-545.

27. C. Blais and R. D.Lyons, "Telepresence: enough is enough," In Proceedings of the International Symposium on Teleoperation and Control, (IFS Publications, Bristol. England), 1988, pp. 217.226.

28. R. Spottiswoode. N.L. Spottiswoode, and C.W. Smith. "Basic principles of the three-dimensional film," Journal of the Society of Motion Picture and Television Engineers., 1952, Vol. 59.

29. A.A. Dumbreck. C.W. Smith., and S.P. Murphy. "The development and evaluation of a stereoscopic television system for use in nuclear environments," in Proceedings of the International Topical Meeting on Remote Systems and Robotics in Hostile Environments. (American Nuclear Society, La Grange Park, IL), 1987, 106-113.

30. D.C. Smith, R.E. Cole, J.O. Merritt, and R.L. Pepper, Remote Operator Performance Comparing Mono and Stereo TV Displays: The Effects of Visibility, Learning and Task Fuciors (Naval Ocean Systems Center Report NOSC TR 380), (Naval Ocean Systems Center, San Diego, CA.), February 1979.

31. K. A. Stevens, and A. Brookes, "Integrating stereopsis with monocular interpretations of planar surfaces," Vision Research, 28 (3), 1988, pp. 371-386.

32. J. V. Draper, Y. Fujita, and J. N. Herndon, Evaluation of High-definition Television for Remote Task Performance (ORNLTM10303). (Oak Ridge National Laboratory, Oak Ridge, TN), 1987.

33. R.L. Pepper, and R.E. Cole. Display System Variables Affecting Operator Performance in Undersea Vehicles and Work Systems (Naval Ocean Systems Center Report NOSC TR 269), (Naval Ocean Systems Center, San Diego, CA), June., 1978.

34. R.K. Jones, and D.N. Lee. "Why two eyes are better than one: The two views of binocular vision," Journal of Experimental Psychology: Human Perception and Performance, 7 (1), 1981, pn. 30-40.

35. J. V. Draper, S. Handel, C. C. Hood, and C. T. Kring. "Three experiments with stereoscopic television: When it works and why," in Proceedings of the 1991 IEEE International Conference on Systems, Man., and Cybernetics, (Institute of Electrical and Electronics Engineers, Richmond, VA), pp. 105-110. 1991.

36. D. Drascic, "Skill acquisition and task performance in teleoperation using monoscopic and stereoscopic video remote viewing," in Proceedings of the Human Factors Society 35th Annual Meeting. (The Human Factors Society, Santa Monica, CA), pp. 1-5. 1991.

37. J. J. Gibson, The Senses Considered as Perceptual Systems. (The Waveland Press. Prospect Heights, IL), 1966.

38. R.K. Jones, and D.N. Lee. "Why two eyes are better than one: The two views of binocular vision," Journal of Experimental Psychology: Human Perception and Performance, 7 (1), 1981, pp. 30-40.

39. J. V. Draper, E. Omori, D. L. Harville, C. A. Wrisberg, and S. Handel. Test Results: The Manipulator Operator Skill Test, (ORNLTM-10524), (Oak Ridge National Laboratory. Oak Ridge. TN). 1987.

40. J. C. Bliss, J. W. Hill, and B. M. Wilber. Tactile Perception Studies Related to Teleoperator Systems (NASA CR-1775), (National Aeronautics and Space Administration, Washington. DC), 1971

41. J. C. Craig, and C. E. Sherrick, "Dynamic tactile displays." in Tactual Perception: A Sourcebook by W. Schiff and E. Foulke (eds.), (Cambridge University Press, Cambridge. England), Chapter 6. pp. 209-233, 1982.

42. D. A. Kugath, Experiments Evaluating Compliance and Force Feedback Effect on Manipulator Performance (NASA-CR-128605), (National Aeronautics and Space Administration. Houston. TX), 1972.

43. J. W. Hill Study of Modeling and Evaluation of Remote Manipulation Tasks with Force Feedback (NASA-CR-158721), (Jet Propulsion Laboratory. Pasadena. CA), 1979..

44. J. W. Hill, and J. K. Salisbury, Jr., Study to Design and Develop Remote Manipulator Systems (NASA-CR-152092), (National Aeronautics and Space Administration. Ames Research Center. Moffett Field, CA), 1977.

45. J. V. Draper. J. N. Herndon, B. S. Weil, and W. E. Moore, "Effects of force reflection on servomanipulator performance," in Proceedings of the International Topical Meeting on Remote Handling and Robotics in Hostile Environments. (American Nuclear Society, LaGrange Park. IL), pp. 654-660, 1987.

46. J. A. Molino and L. J. Langley. "Training novice operntors to use a teleoperated robot for remote, dexterous operations," in Proceedings of the ANS Third Topical Meeting on Robotics and Remote Systems, (Savannah River Laboratory, Aiken, SC), 1989.

47. B. Hannaford, L. Wood, D. A. McAffee, and H. Zak, "Performarce evaluation of a six-axis generalized force-reflecting teleoperator," IEEE Transactions on Man, Systems., and Cyberneticr, 21(3), pp. 620-633, 1991.

48. R. C. Hendrich. J. M. Bierschwale. M. K. Manahan, M. A. Stuart, and A. J. Legendre, "Evaluation of force-torque displays for use with space station telerobotic activities," in Fifth Annual Workshop on Space Operations Automation and Robotics (SOAR '91) (NASA Conference Publication 3127), by K. Krishen (ed.), (National Aeronautics and Space Administration, Johnson Space Flight Center. Houston, TX), pp 454.459, 1991.

49. M. J. Massimino and T. B. Sheridan, "Using auditory displays for force feedback," in Telemanipulator Technology, Hari Das, Editor, Proc. SPIE 1833. pp. 325-336, 1993.

50. R. B. Greenway, Jr. and T. N. Faddis, "Effects of tactile information on telerobotic performance, in Telemanipulator Technology, Hari Das, Editor. Proc. SPIE 1833, pp. 317-324, 1993. 
51. V. Lumelsky, On human performance in telerobotics, IEEE Transactions on Man, Systems., and Cybernetics, 21(5), 971-982, 1991.

52. J. L. Knight, "Manual control and tracking," in G. Salvendy (Ed.), Handbook of Human Factors. New York. NY: John Wiley \& Sons, 1987, pp. 182-218.

53. S. W. Keele, "Motor control," in K. R. Boff, L. Kaufman, \& J. P. Thomas (Eds.), Handbook of Perception and Human Performance, Volume 2: Cognitive Processes and Performance. New York, NY: John Wiley \& Sons, 1986, Chapter 30.

54. C. D. Wickens, Engineering Psychology and Human Performance. Columbus, OH: Charles E. Merrill Publishing Company, 1982.

55. R. J. Jagacinski, "Target acquisition: performance measures, process models, and design implications," in G. R. McMillan, D. Beevis, E. Salas, M. H. Strub, R. Sutton, and L. van Breda (Eds.), Applications on Human Performance Models to System Design. New York, NY: Plenum Press, 1989, pp. 135-149.

56. D. Bullock \& S. Grossberg, "Neural dynamics of planned arm movements: emergent invariants and speed-accuracy properties during trajectory formation," Psychological Review, vol. 95 no. 1, pp. 49-90, 1988.

57. R. A. Schmidt, Motor learning and control. Champaign, IL: Human Kinetics Publishers, 1982.

58. R. J. Jagacinski, D. W. Repperger, M. S. Moran, S. L. Ward, \& B. Glass, "Fitts' Law and the microstructure of rapid discrete movements," Journal of Experimental Psychology: Human Perception and Performance, vol. 6 no. 2, pp. 309-320, 1980.

59. T. L. Brooks, Telerobot Response Requiremenis: A Position Paper on Control Response for the FTS Telerobot (Report No. STX/ROB/90-03). Lanham, MD: ST Systems Corporation, 1990.

60. D. A. Meyer, R. A. Abrams, S. Komblum, C. E. Wright, \& J. E. K Smith, "Optimality in human motor performance: Ideal control of rapid aimed movements," Psycholingical Review, vol. 95, pp. 340-370, 1988.

61. J. V. Draper. "Hand acceleration impulse bandwidth during target acquisition," IEEE Transactions on Man, Systems., and Cybernetics, in press.

62. J. V. Draper and S. Handel, "Teleoperator movement time and acceleration bandwidth during Fitts' task," manuscript submitted for publication.

63. J. V. Draper and S. Handel, "Periodic components of hand acceleration/deceleration impulses during telemanipulation," this volume.

64. R. Goertz, "Some work on manipulator systems at ANL past, present, and a look at the future," in Proceedings of the 1964 Seminars on Remotely Operated Special Equipment (CONF-640508), (United States Atomic Energy Commission, Division of Technical Information, Germantown. MD), pp. 27-69, 1964.

65. J. V. Draper and S. Handel, "End-effector velocity and input frequency effects on teleoperator performance," Proceedings of the Human Factors Society 33rd Annual Meeting, 584-588, October, 1989.

66. J. V. Draper. S. Handel, and C. C. Hood, "Fitts' task by telemanipulator: Movement time, velocity, and acceleration," Proceedings of the Human Factors Society 34th Annual Meeting, 127-131. October, 1990.

67. J. V. Draper. E. Sundstrom, and J. N. Herndon, "Joint motion clusters in servomanipulator operations," in Proceedings of the Human Factors Society 30th Annual Meeting, (The Human Factors Society, Santa Monica, CA), pp. 552-555, 1986.

68. J. V.Draper, S. Handel, and C. C. Hood, "The impact of partial joint failure on teleoperator task performance," in Robotics and Remote Systems: Proceedings of the Fourth ANS Topical Meeting on Robotics and Remote Systems, by M. Jamshidi and P. J. Eicker (eds.;, (Sandia National Laboratory, Albuquerque, NM), pp. 433-439, 1991.

69. A. K. Bejczy, "Sensors, controls, and man-machine interface for advanced teleoperation," Science, 208(4450), $1327-1335,1980$.

70. A. K. Bejczy, R.S. Dotson, and F. P. Mathur, "Man-machine speech interaction in a teleoperator environment," in Proceedings of the Department of Defense Symposium on Voice Interactive System. (DOD Human Factors Group, Dallas, TX), pp. 1-16, 1980:

71. A. K. Bejczy, R. S. Dotson, J. W. Brown, and J. L. Lewis, "Voice control of the space shuttle video system," in Proceedings of the I7th Annual Conference on Manual Control. (UCLA Press, Los Angeles, CA), pp. 627-64, 19810.

72. R. Frenette, Evaluation of Video-Camera Controls for Remote Manipulation, Unpublished Masters Degree Thesis, University of British Columbia, 1985.

73. J. V. Draper. Manual, Voice., and Automated Control of a Teleoperator Viewing System. Unpublished Doctoral Thesis, University of Tennessee at Knoxville, 1987.

74. T. L. Brooks, I. Ince, and G. Lee, "Operator vision aids for space teleoperation assembly and servicing,." in Fifth Annual Workshop on Space Operations Automation and Robotics (SOAR '91) (NASA Conference Publication 3127), by K. Krishen (ed.), (National Aeronautics and Space Administration, Johnson Space Flight Center, Houston, TX), pp. 412-421, 1991.

75. J. V. Draper, S. Handel, and C. T. Kring, "Design of a multisystem remote maintenance control room," in Proceedings of the International Atomic Energy Agency International Conference on Man-machine Interface in the Nuclear Industry, (International Atomic Energy Agency, Tokyo, Japan), pp. 252-256, 1988.

76. M. M. Clarke, and J. G. Kreifaldt, Robothuman interaction: a challenge for job design. In Proceedings of the Human Factors Society 28th Annual Meeting. (The Human Factors Society, Santa Monica. CA), pp. 904-907. 1984.

77. M. M. Clarke, J. G. Kreifeldt, and J. V. Draper, Man/Machine Interface for a Nuclear Cask Remote Handling Control Station: System Design Requirements (Report No. HEDL-7465), (Hanford Engineering Development Laboratory, Richland, WA), 1984.

78. M. M. Clarke, and J. G. Kreifeldt, "A control room concept for remote maintenance in high-radiation areas," in Procecdings of the Human Factors Society 28th Annual Meeting, (The Human Factors Society, Santa Monica, CA), pp. 230-235, 1984. 
79. C. C. Hood, J. V. Draper, and S. Handel, "Activity and cooperation in a multi-person teleoperator cockpit," in Proceedings of the Human Factors Society 34th Annual Meeting, (The Human Factors Society, Santa Monica, CA), pp. 660-663, 1990.

80. D. Burgy, C. Lempges, A. Miller, L. Schroeder, H. Van Cott, \& B. Paramore, Task analysis of nuclear power plant control room crews: Project approach and methodology (NUREC/CR-3371, Vol. 1-4). Washington, DC: U.S. Nuclear Regulatory Commission, 1983.

81. J. B. Chesser, BRET Rack Remote Maintenance Demonstration Test Report (ORNLTM-10875), (Oak Ridge National Laboratory, Oak Ridge, TN), 1988.

82. N. Hogan, "Controlling impedance at the man/machine interface," in Proceedings of the 1989 IEEE International Conference on Robotics and Automation, (IEEE Computer Society Press, Washington, DC), 1989, pp. 1626-1631.

83. C. R. Flatau, "The manipulator as a means of extending our dexterous capabilities to larger and smaller scales," in Transactions of the American Nuclear Society 21 st Conference on Remote Systems Technology, (American Nuclear Society, LaGrange Park, IL), pp. 19. 22, 1973.

84. N. S. Rasor and J. W. Spickler, "Endocorporeal surgrery using remote manipulators," in Remotely Manned Systems: Exploration and Operation in Space, by E. Heer (ed.), (California Institute of Technology, Pasadena, CA), pp. 483-492, 1973.

85. N. Jordan. "Allocation of functions between man and machines in automated systems." Journal of Applied Psychology, 47(3), 161$165,1963$. 

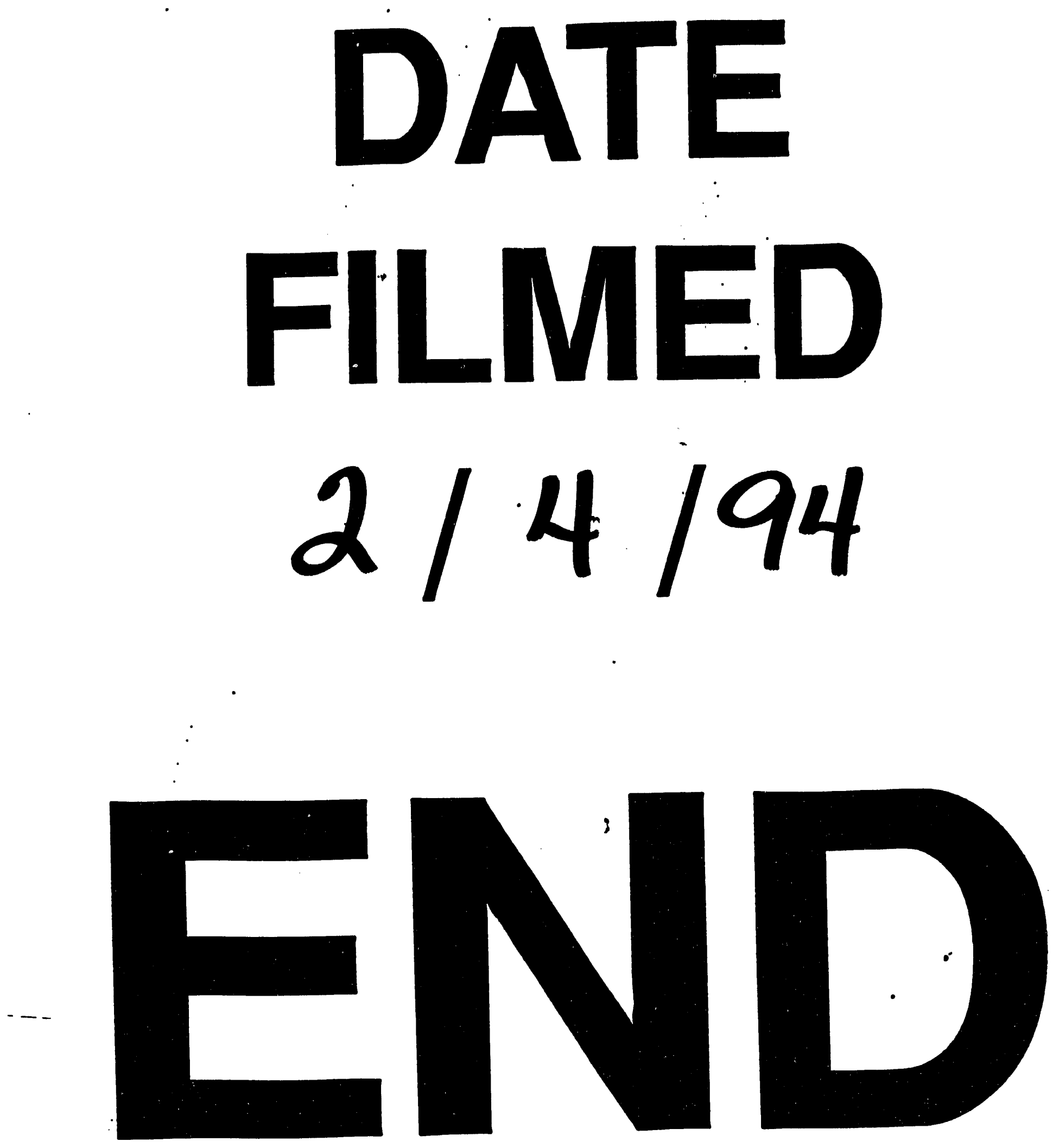
